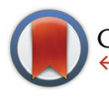

CrossMark click for updates

Cite this: Org. Biomol. Chem., 2017, 15, 1970

Received 19th December 2016, Accepted 3rd February 2017

DOI: $10.1039 / c 6 o b 02770 a$

rsc.li/obc

\section{Photocatalytic esterification under Mitsunobu reaction conditions mediated by flavin and visible light $\dagger$}

\author{
M. März, ${ }^{a}$ J. Chudoba, ${ }^{b}$ M. Kohout ${ }^{a}$ and R. Cibulka*a
}

\begin{abstract}
The usefulness of flavin-based aerial photooxidation in esterification under Mitsunobu reaction conditions was demonstrated, providing aerial dialkyl azodicarboxylate recycling/generation from the corresponding dialkyl hydrazine dicarboxylate. Simultaneously, activation of triphenylphosphine $\left(\mathrm{Ph}_{3} \mathrm{P}\right)$ by photoinduced electron transfer from flavin allows azo-reagent-free esterification. An optimized system with 3-methylriboflavin tetraacetate (10\%), oxygen (terminal oxidant), visible light (450 nm), $\mathrm{Ph}_{3} \mathrm{P}$, and dialkyl hydrazine dicarboxylate (10\%) has been shown to provide efficient and stereoselective coupling of various alcohols and acids to esters with retention of configuration.
\end{abstract}

A systems of triphenylphosphine $\left(\mathrm{Ph}_{3} \mathrm{P}\right)$ or a related phosphine activated by an oxidant allow efficient esterification under mild conditions. ${ }^{1}$ In the Mitsunobu reaction, ${ }^{2,3} \mathrm{PPh}_{3}$ is oxidized by a dialkyl azodicarboxylate (usually DEAD [1a] or DIAD [1b]) to form a betain species, which facilitates transformation of an alcohol to a reactive alkoxyphosphonium intermediate (Scheme 1). The latter undergoes $\mathrm{S}_{\mathrm{N}} 2$ substitution with carboxylate giving an ester with inversion of configuration. There are a few cases in which an acyloxyphosphonium intermediate predominates under Mitsunobu reaction conditions, subsequent $S_{N} A c$ substitution of which gives the product with retention of configuration. ${ }^{4-6}$

The Mitsunobu reaction has become an extremely useful tool in organic synthesis. ${ }^{3 b, 7}$ However, its further expansion, in particular towards large-scale applications, is limited by the need for a stoichiometric amount of oxidant, azodicarboxylate 1 , which is toxic and unstable and the use of which generates dialkyl hydrazine dicarboxylate 2 as a waste by-product. An attempt to solve this problem led to recent pioneering studies on catalytic Mitsunobu reaction. ${ }^{1 b}$ Toy

\footnotetext{
${ }^{a}$ Department of Organic Chemistry, University of Chemistry and Technology, Prague, Technická 5, 16628 Prague, Czech Republic. E-mail: cibulkar@vscht.cz

${ }^{b}$ Central Laboratories, University of Chemistry and Technology, Prague, Technická 5, 16628 Prague, Czech Republic

$\dagger$ Electronic supplementary information (ESI) available: Experimental section and copies of NMR spectra and HPLC chromatograms. See DOI: 10.1039/ c6ob02770a
}

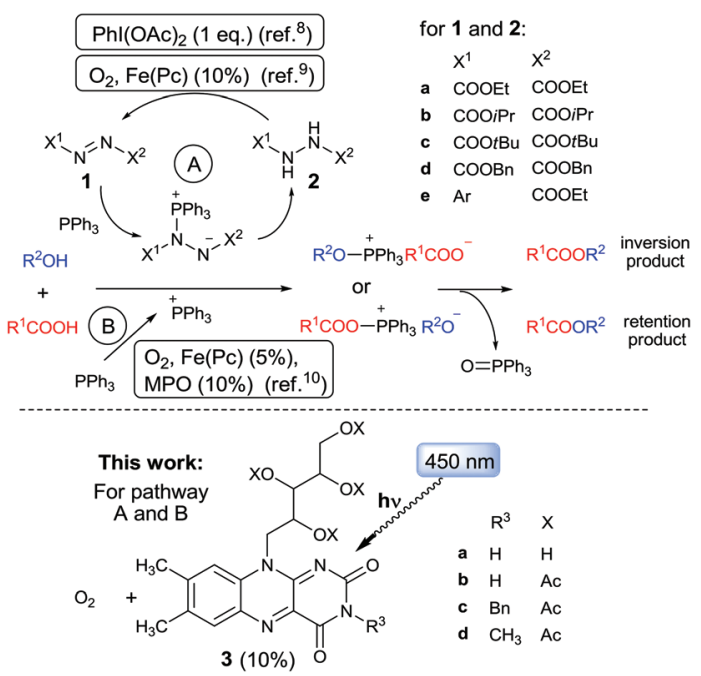

Scheme 1 Catalytic esterification mediated by activated $\mathrm{Ph}_{3} \mathrm{P}$ under Mitsunobu (A) and azo-reagent-free (B) conditions.

and co-workers applied a stoichiometric amount of the oxidant $\mathrm{PhI}(\mathrm{OAc})_{2}$ to convert the generated hydrazine 2a back to azo compound 1a, allowing only $10 \mathrm{~mol} \% \mathbf{1 a}$ to be used. ${ }^{8}$ Taniguchi, et al. developed and optimized catalytic Mitsunobu reaction using ethyl $N$-aryl-azocarboxylates 1e (10 mol\%) instead of $\mathbf{1 a}$ or $\mathbf{1 b}$, in conjunction with a catalytic amount (10 mol\%) of $\mathrm{Fe}(\mathrm{II})$-phthalocyanine (Fe[Pc]), which reoxidized arylhydrazine, being simultaneously re-generated by air oxygen..$^{9}$ Notably, Fe[Pc] was not able to recycle original Mitsunobu reagents, DEAD or DIAD, due to high oxidation potential of corresponding hydrazines 2 . Another approach is to use a procedure free from azo reagent 1 in which $\mathrm{PPh}_{3}$ is activated by aerial oxidation catalyzed by $\mathrm{Fe}[\mathrm{Pc}]$. This esterification occurs via an acylphosphonium intermediate giving an ester with retention of configuration. ${ }^{10}$ Another problem of the Mitsunobu type reactions is bulk production of phosphine oxide. O'Brien ${ }^{11}$ and later Aldrich and Buonomo ${ }^{12}$ showed that phosphine oxide can be reduced in situ with 
phenylsilane, thus allowing use of the phosphine reagent in a catalytic amount. ${ }^{13}$

We surmise that, due to their redox character, Mitsunobutype reactions represent a typical challenge for photoredox catalysis, ${ }^{14}$ which have undergone rapid development in recent years. Upon excitation, molecules become stronger oxidizing agents compared to their ground-state forms, which considerably extends the possibilities for regeneration of Mitsunobu reagents or alternative activation of phosphines. However, to the best of our knowledge, no application of photoredox catalysis in catalytic Mitsunobu reactions or phosphine-mediated esterifications has hitherto been reported. Herein, we present a photocatalytic system (Scheme 1) based on flavin 3d (a derivative of vitamin B2 [3a]), oxygen, and visible light, which is able to regenerate commercial dialkyl azodicarboxylates 1 . The system was found to simultaneously activate $\mathrm{Ph}_{3} \mathrm{P}$ by photoinduced electron-transfer, thus providing azo-reagentfree esterification.

Our original idea to regenerate azodicarboxylates $\mathbf{1}$ from the corresponding hydrazides 2 led us to flavin photocatalysts. ${ }^{15,16}$ Upon excitation with blue light (450 nm), flavins become oxidizing agents ${ }^{17}\left(E_{\text {red }}^{*}=1.67 \mathrm{~V} v s\right.$. SCE for riboflavin tetraacetate (3b)), strong enough to oxidize 2 (a value of $E_{\mathrm{ox}}^{*}=1.62 \mathrm{~V} v s$. SCE has been reported for BocNHNHBoc${ }^{18}$ ), but not so strong as to mediate undesired oxidation of alcohols, even when they are activated, e.g. benzyl alcohols, which are often substrates of Mitsunobu reactions. The only exceptions are electron-rich benzyl alcohols such as 4-methoxybenzyl alcohol $\left(E_{\mathrm{ox}}^{*}=1.43 \mathrm{Vvs}\right.$. SCE (ref. 19)), which is a traditional substrate for testing flavins in photooxidations. ${ }^{16 e, 17,20}$ Importantly, flavins can be converted back to their oxidized forms by oxygen, and can thus be applied in catalytic amounts (cf. Scheme 2). ${ }^{15}$

Preliminary experiments confirmed that $\mathbf{3 b}$ oxidizes dialkyl hydrazine-dicarboxylates $\mathbf{2 a - d}$ to the corresponding azo com-

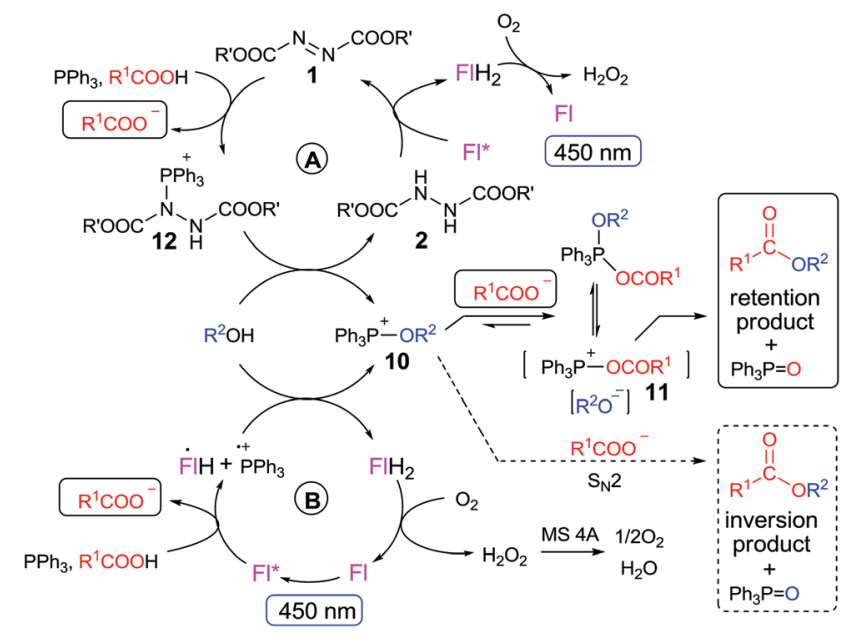

Scheme 2 Proposed mechanism of flavin (Fl)-mediated photocatalytic esterification with (A) and without (B) contribution from azodicarboxylate 1. pounds 1 when irradiated by light of wavelength $450 \mathrm{~nm}$ (see ESI $\dagger$ ). The oxidation proceeded remarkably in acetonitrile, and thus we used this solvent in model photocatalytic esterification with 3-nitrobenzoic acid $\mathbf{4 a}$ and benzyl alcohol 5a using $10 \mathrm{~mol} \%$ of $\mathbf{3 b}, 10 \mathrm{~mol} \%$ of $\mathbf{1 b}$, and 2 equivalents of $\mathrm{PPh}_{3}$ (Table 1). The reaction was performed at $25^{\circ} \mathrm{C}$ under oxygen and irradiation with a blue diode $(450 \mathrm{~nm})$, in the presence of molecular sieves $(4 \AA)$ to remove hydrogen peroxide formed during flavin regeneration. ${ }^{9 c}$ To our delight, we observed formation of ester $\mathbf{6 a}$ in moderate conversion after $24 \mathrm{~h}$ (entry 1 ), and a positive result was found even when $\mathbf{2 b}(10 \mathrm{~mol} \%)$ was used instead of $\mathbf{1 b}$ (entry 2). Only a small amount of aldehyde was formed with $\mathbf{3 b}$, confirming the suitability of flavins in this reaction. Use of stronger oxidants, such as 9-mesityl-10-methylacridinium perchlorate $\left(7 ; E_{\text {red }}^{*}=2.08 \mathrm{~V} v\right.$ s. SCE (ref. $\left.\left.14 a\right)\right)$ or triphenylpyrylium tetrafluoroborate $\left(8 ; E_{\text {red }}^{*}=2.45 \mathrm{~V} v s\right.$. SCE (ref. 14a)) preferentially led to benzylic oxidation (entries 3 and 4). Notably, the $\mathrm{N}-\mathrm{H}$ bond in flavins is sufficiently acidic for $\mathbf{3} \mathbf{b}$ to be a substrate of Mitsunobu reaction. We observed formation of $\mathrm{N}$-benzyl derivative 3c, which was still active in esterification, but less than $\mathbf{3 b}$ ( $c f$. entries 2 and 5). Thus, $N$-methylflavin $3 \mathbf{d}$ seemed to be a good choice of photocatalyst (entries 6 and 7).

Monitoring the reaction course showed undesired direct oxidation of $\mathrm{Ph}_{3} \mathrm{P}$ to $\mathrm{Ph}_{3} \mathrm{P}=\mathrm{O}$, which retarded ester formation. We assume that excited flavin participates in this oxidation by electron transfer from $\mathrm{Ph}_{3} \mathrm{P}\left(E_{\mathrm{Ox}}=1.06\right.$ vs. $\left.\mathrm{SCE}^{21}\right)$ (for quenching experiment, see ESI $\dagger$ ). The formed $\mathrm{Ph}_{3} \mathrm{P}^{\cdot+}$ reacts with oxygen to form phosphine oxide, which is known to occur by several mechanisms. ${ }^{22}$ This side reaction can be suppressed by

Table 1 Optimization of protocol for photocatalytic Mitsunobu reaction with recycling/generation of 1

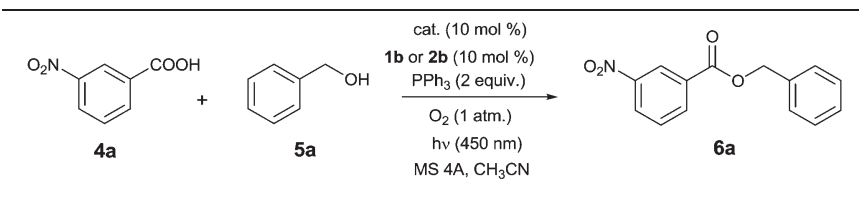

\begin{tabular}{|c|c|c|c|c|}
\hline \multirow[b]{2}{*}{ Entry } & \multirow[b]{2}{*}{ Catalytic system } & \multirow[b]{2}{*}{$\operatorname{Temp}\left[{ }^{\circ} \mathrm{C}\right]$} & \multicolumn{2}{|c|}{$\begin{array}{l}\text { Conversion after } \\
24 \mathrm{~h}[\%]\end{array}$} \\
\hline & & & Ester & Aldehyde \\
\hline 1 & $3 \mathbf{b} / \mathbf{1} \mathbf{b}$ & 25 & 58 & 2 \\
\hline 2 & $3 \mathbf{b} / 2 \mathbf{b}$ & 25 & 48 & 2 \\
\hline 3 & $7 / 2 \mathbf{b}$ & 25 & 46 & 31 \\
\hline 4 & $8 / 2 b$ & 25 & 8 & 20 \\
\hline 5 & $3 \mathbf{c} / 2 \mathbf{b}$ & 25 & 41 & 7 \\
\hline 6 & $3 d / 1 b$ & 25 & 64 & 2 \\
\hline 7 & $3 \mathbf{d} / 2 \mathbf{b}$ & 25 & 60 & 2 \\
\hline $8^{a}$ & $3 \mathbf{d} / 2 \mathbf{b}$ & 25 & 79 & Trace \\
\hline $9^{b}$ & $3 \mathbf{d} / 2 \mathbf{b}$ & 25 & 85 & Trace \\
\hline 10 & $3 \mathbf{d} / \mathbf{2 b}$ & 50 & 66 & Trace \\
\hline $11^{b}$ & $3 d / 2 b$ & 50 & 92 & Trace \\
\hline 12 & $3 \mathbf{d} /-$ & 25 & 17 & 2 \\
\hline $13^{b}$ & $3 \mathbf{d} /-$ & 25 & 26 & - \\
\hline 14 & $3 \mathbf{d} /-$ & 50 & 47 & 2 \\
\hline $15^{b}$ & $3 \mathbf{d} /-$ & 50 & 69 & - \\
\hline
\end{tabular}

${ }^{a} \mathrm{PPh}_{3}$ added in three portions at the time 0,4 and 8 hours. ${ }^{b} \mathrm{PhSiH}_{3}$ ( 2 equiv.) added. 
subsequent addition of $\mathrm{PPh}_{3}$, which increases the yield significantly (entry 8). A similar effect was achieved by adding $\mathrm{PhSiH}_{3}{ }^{12}$ for in situ reduction of $\mathrm{Ph}_{3} \mathrm{P}=\mathrm{O}$ back to $\mathrm{Ph}_{3} \mathrm{P}$ (entry 9). Notably, positive effects of elevated temperature on the reaction in both the absence and presence of $\mathrm{PhSiH}_{3}$ were observed, achieving yields of up to $92 \%$ (entries 10 and 11). It should be noted that formation of $\mathbf{6 a}$ was not observed in blank experiments (see ESI $\dagger$ ) in the absence of the flavin photocatalyst, light, $\mathrm{Ph}_{3} \mathrm{P}$ or molecular sieves.t On the other hand, a little 6a was formed with omission of the azo compound or its precursor, irrespective of the presence of $\mathrm{PhSiH}_{3}$ (entries 12 and 13). The amount of ester formed by the azofree process was increased at elevated temperature (entries 14 and 15).

Taking into account conversions of ester $\mathbf{6 a}$ achieved in the presence and absence of $\mathbf{2 b}$ ( $c f$. entries 7 vs. 12, 9 vs. 13, $10 v s$. 14, and 11 vs. 15), the initial results gave evidence that: (i) after irradiation, flavin 3d can mediate a Mitsunobu reaction that is catalytic in azo reagent by virtue of its generation/recycling from the corresponding hydrazine; (ii) another mechanistic pathway not requiring the azo component is involved, especially at elevated temperature. Such a "background" reaction has been analogously observed using recycling systems with $\mathrm{PhI}(\mathrm{OAc})_{2}{ }^{8}$ and $\mathrm{Fe}(\mathrm{II})$-phthalocyanine. ${ }^{9 c}$
Next, we examined the substrate scope of photocatalytic esterification alternating various alcohols 5 (Table 2) and acids 4 (Table 3) under selected conditions: (i) without $\mathrm{PhSiH}_{3}$ with $10 \%$ of $1 \mathrm{~b}$ at $25{ }^{\circ} \mathrm{C}$, characterized by a major contribution from the azo-compound-mediated reaction (method I, analogous to entry 6 in Table 1), and (ii) with $\mathrm{PhSiH}_{3}$ and $10 \%$ of $\mathbf{2 b}$ at $50{ }^{\circ} \mathrm{C}$, whereupon the non-azo-reagent-free pathway predominated (method II, analogous to entry 11 in Table 1). In the Tables 2 and 3, the efficacy of both methods is characterized by conversions and preparative yields of esters after $24 \mathrm{~h}$. Conversions of photocatalytic esterifications in the absence of azo reagent $\mathbf{1 b}$ or its precursor $\mathbf{2} \mathbf{b}$ are given for comparison to estimate the contribution of azo-reagent-free pathway (blank).

Method I (Table 2, odd entries) provided moderate to good conversions and yields of esters $\mathbf{6 a - h}$ by esterification of 3-nitrobenzoic acid (4a) with substituted benzyl alcohols regardless of the character and position of the substituent.

Octyl ester 6k (representative of esters with aliphatic alcohols) was also obtained in good yield by method I while ester 6i with 2-phenylethanol (5i) was formed in poor conversion only (entries 17 and 19). On the other hand, at elevated temperature (method II), high conversions and good to high yields of esters $\mathbf{6 a}-\mathbf{k}$ were achieved with all alcohols investigated (Table 2, even entries). As could be expected, significant

Table 2 Substrate scope of photocatalytic esterification (various alcohols)

\begin{tabular}{|c|c|c|c|c|c|}
\hline Entry & Product & $\operatorname{Method}^{a}$ & Conv. $[\%]$ & Yield $^{b}[\%]$ & Conv. (blank) $)^{c}[\%]$ \\
\hline 1 & & I & $64^{d}$ & 53 & 17 \\
\hline 2 & & II & 92 & 82 & 69 \\
\hline 3 & & $\mathrm{I}$ & 73 & 65 & 21 \\
\hline 4 & & II & Quant. & 85 & 80 \\
\hline 5 & & I & 67 & 60 & 25 \\
\hline 6 & & II & Quant. & 79 & 80 \\
\hline 7 & & I & 64 & 54 & 60 \\
\hline 8 & & II & 82 & 72 & 75 \\
\hline 9 & & $\mathrm{I}$ & $62^{e}$ & 54 & 28 \\
\hline 10 & & II & $76^{f}$ & 65 & 40 \\
\hline 11 & & I & $50^{g}$ & 39 & 39 \\
\hline 12 & & II & $85^{h}$ & 71 & 68 \\
\hline 13 & & I & 52 & 46 & 46 \\
\hline 14 & & II & 78 & 60 & 59 \\
\hline 15 & & I & 53 & 44 & 43 \\
\hline 16 & & II & 78 & 71 & 68 \\
\hline 17 & & I & 18 & n.d. & 10 \\
\hline 18 & & II & Quant. & 80 & 20 \\
\hline 19 & & I & 51 & 39 & 22 \\
\hline 20 & & II & 72 & 61 & 63 \\
\hline
\end{tabular}

${ }^{a}$ Conditions for method I: $n(5)=0.15 \mathrm{mmol}, n(\mathbf{4})=0.18 \mathrm{mmol}, n(\mathbf{3 d})=0.015 \mathrm{mmol}, n(\mathbf{1 b})=0.015 \mathrm{mmol}, n\left(\mathrm{PPh}_{3}\right)=0.3 \mathrm{mmol}, \mathrm{MS} 4 \AA(150 \mathrm{mg})$, $2 \mathrm{ml} \mathrm{CH} \mathrm{CHN}_{3} \mathrm{CN}, 455 \mathrm{~nm}, 25{ }^{\circ} \mathrm{C}, 24 \mathrm{~h}$; for method II: $2 \mathrm{~b}$ instead of $\mathbf{1 b}$; additionally $0.3 \mathrm{mmol}$ of $\mathrm{PhSiH}_{3} ; 50{ }^{\circ} \mathrm{C} .{ }^{b}$ Preparative yield. ${ }^{c} \mathrm{Conversion}$ of esterification in the absence of $\mathbf{1 b}$ (method I) or $\mathbf{2 b}$ (method II) from ${ }^{1} \mathrm{H}$ NMR data. ${ }^{d} 80 \%$ after 72 h. ${ }^{e} 14 \%$ of aldehyde. ${ }^{f} 7 \%$ of aldehyde. ${ }^{g} 18 \%$ of aldehyde. ${ }^{h} 15 \%$ of aldehyde. 
Table 3 Substrate scope of photocatalytic esterification (various acids)

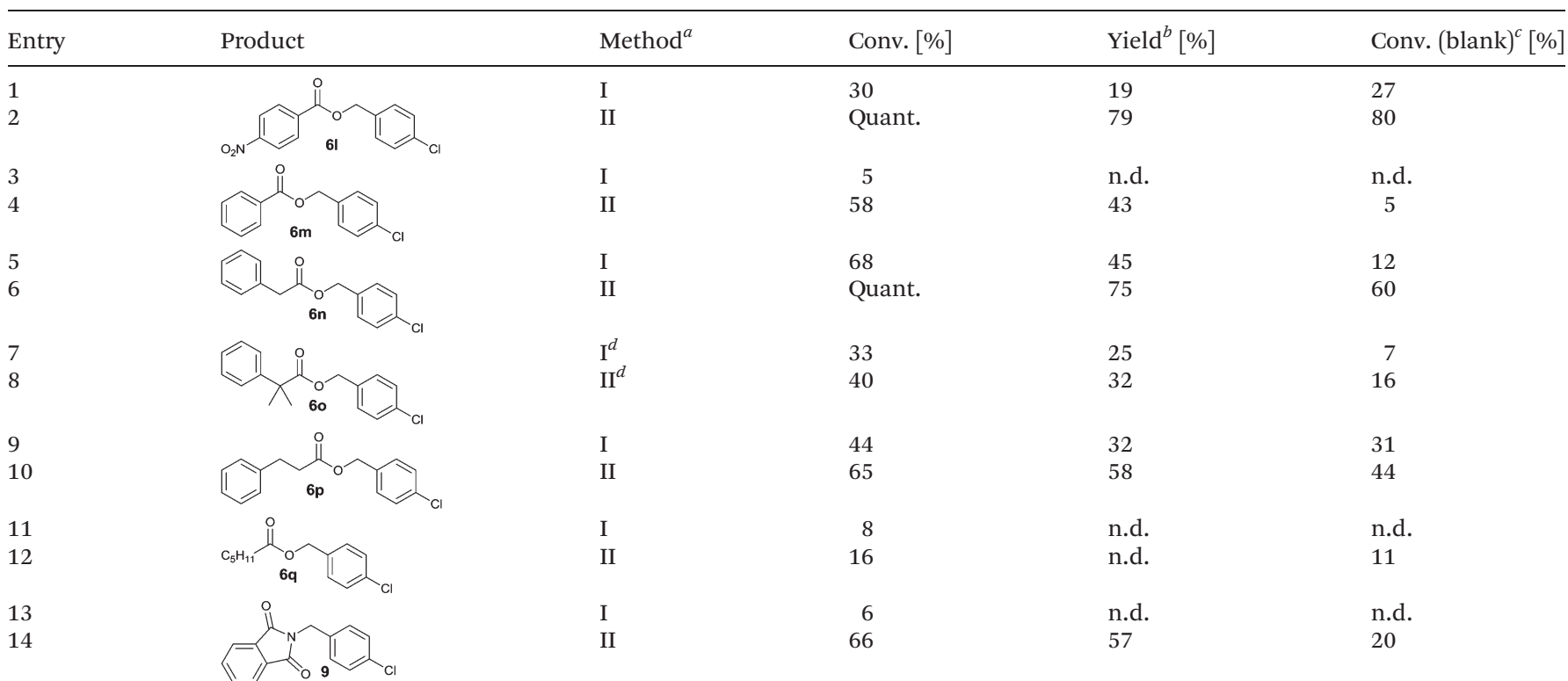

${ }^{a}$ Conditions for method I: $\left.n(\mathbf{5})=0.15 \mathrm{mmol}, n(\mathbf{4})=0.18 \mathrm{mmol}, n(\mathbf{3 d})=0.015 \mathrm{mmol}, n(\mathbf{1 b})=0.015 \mathrm{mmol}, n\left(\mathrm{PPh}_{3}\right)=0.3 \mathrm{mmol}, \mathrm{MS} 4 \AA \AA^{150 \mathrm{mg}}\right)$, $2 \mathrm{ml} \mathrm{CH} 3 \mathrm{CN}, 455 \mathrm{~nm}, 25{ }^{\circ} \mathrm{C}, 24 \mathrm{~h}$; for method II: $2 \mathbf{b}$ instead of $\mathbf{1 b}$; additionally $0.3 \mathrm{mmol}^{\circ} \mathrm{PhSiH}_{3}$; $50{ }^{\circ} \mathrm{C}$. ${ }^{b}$ Preparative yield. ${ }^{c}$ Conversion of esterification in the absence of $\mathbf{1 b}(\operatorname{method} \mathrm{I})$ or $\mathbf{2 b}(\operatorname{method} \mathrm{II})$ from ${ }^{1} \mathrm{H}$ NMR data. ${ }^{d} 72 \mathrm{~h}$.

amount of benzaldehyde (15-28\%) was formed during esterification of 4-methyl- (5e) and 4-methoxybenzyl (5f) alcohols because of their low oxidation potentials (entries 9-12) ${ }^{19}$ Both methods proved to be effective for secondary alcohols, albeit requiring longer reaction times (Table 4).

Besides $\mathbf{4 a}$, other aromatic acids (4-nitrobenzoic [4b] and benzoic acid [4c]) as well as phenylalkanoic acids (phenylacetic [4d] and 3-phenylpropanoic acid [4f]) gave good to high yields of esters 61-n and 6p with 4-chlorobenzyl alcohol (5b) by method II (Table 3, even entries). For these acids, method I seemed to be less efficient giving lower yields of $\mathbf{6 n}$ and $\mathbf{6 p}$ (entries 5 and 9) and almost no ester $\mathbf{6 m}$ (entry 3). Interestingly, both methods afforded ester 60 with sterically hindered $\alpha, \alpha$-disubstituted acid $4 \mathrm{e}$ albeit in low yields and after prolonged reaction time (entries 7 and 8). Low efficacy of our protocols was shown for esterification of hexanoic acid $(\mathbf{4 g})$ as a representative of non-substituted aliphatic acids (entries 11 and 12). Method II was proved to be usefull also for phthalimide as a representative of $N$-nucleophile (entry 14).

Notably, a significant contribution of azodicarboxylate $\mathbf{1 b}$ or its precursor $\mathbf{2 b}$ was observed with most substrates (Tables 2 and 3 , cf. conversions of methods I or II with azo-free

Table 4 Stereoselectivity of photocatalytic esterification

\begin{tabular}{llllll}
\hline Entry & Alcohol & Method $^{a}$ & Conv. $^{b}[\%]$ & Yield $^{c}[\%]$ \\
\hline 1 & Product & I & \\
er $^{d}$ \\
\hline
\end{tabular}

${ }^{a}$ For conditions, see Table 2; reaction time: $72 \mathrm{~h} .{ }^{b}$ Conversion of esterification in the presence/in the absence of $\mathbf{1 b}$ (method I) or $\mathbf{2 b}$ (method II) from ${ }^{1} \mathrm{H}$ NMR data. ${ }^{c}$ Preparative yields. ${ }^{d}$ From HPLC, see ESI. ${ }^{e}$ er $98: 2$ was found in the absence of $2 \mathbf{b}$. 
pathway [blank]). This contribution became even more pronounced for esterification of some benzylic esters, e.g. 6a-6c and 6e (Table 2, entries 1, 3, 5 and 9), provided by method I or for some esterifications by method II, e.g. towards $6 \mathbf{i}$ (Table 2, entry 18), 6m and 9 (Table 3, entries 4 and 14). On the other hand, in some cases, especially for method II, azo-free reaction pathway predominates as indicated by high conversions of blank. The conversions of esters are indeed high under optimal conditions (method II) but not quantitative in many cases. The reason is probably bleaching of the flavin photocatalyst which was observed during esterifications. Similar photodecomposition of flavins was reported to occur also during other photocatalytic processes. ${ }^{15,16,20}$

Irrespective of the method, highly stereoselective production of esters (Table 4) with retention of configuration was observed for two types of secondary alcohols, 1-phenylethanol (5l, entries 1-4) and ethyl lactate (5m, entries 5-8), indicating that our photocatalytic esterification occurs not through alkoxyphosphonium 10 but through acylphosphonium species 11 (see Scheme 2). This intermediate must also predominate in the photocatalytic "Mitsunobu reaction pathway" occurring through betain intermediate 12 (Scheme 2A), as indicated by the very high stereoselectivities observed with 51 at $25{ }^{\circ} \mathrm{C}$ (method I), i.e. at the conditions where a significant contribution of the catalytic amount of $\mathbf{1 b}$ was detected (entries 1 and $3, c f$. conversions in the presence and the absence of $\mathbf{1 b}$ ). Most probably, our photocatalytic esterification just met the conditions favoring acyloxyphosphonium species $\mathbf{1 1}$ in the delicate acyloxy/alkoxyphosphonium equilibrium. ${ }^{5}$ Notably, the inversion product predominated ( $\mathrm{er}=85: 15 \S)$ in standard (stoichiometric) Mitsunobu esterification of $\mathbf{5 l}$, but it is not formed exclusively indicating not only $\mathrm{S}_{\mathrm{N}} 2$ mechanism is involved.

Based on literature data and our own experimental results, we propose a mechanism for the pathway not involving the azo compound or its hydrazine precursor (Scheme 2B). Excited flavin $\mathbf{F l}^{*}$ oxidizes $\mathrm{Ph}_{3} \mathrm{P}$ to $\mathrm{Ph}_{3} \mathrm{P}^{{ }^{+}}$, as it is evident from the redox potentials (see above) and confirmed by the observation of efficient emission quenching $\left(K_{\mathrm{S}}=22 \mathrm{~L} \mathrm{~mol}^{-1}\right.$; for the Stern-Volmer plot, see ESI $\dagger$ ). The flavin radical anion ( $\mathrm{p} K_{\mathrm{a}}$ of conjugated acid is 8.4 , ref. 23 ) is immediately protonated by a carboxylic acid to form radical $\mathbf{F l H} \cdot \mathbf{P h}_{3} \mathrm{P}^{\cdot+}$ then reacts with an alcohol to form (after subsequent oxidation and deprotonation) an alkoxyphosphonium species 10, which is in equilibrium with the corresponding acyloxyphosphonium species 11. Nevertheless, 11 may also be formed directly from $\mathrm{Ph}_{3} \mathrm{P}^{\bullet^{+}}$ and carboxylate. $\uparrow$ Finally, 11 undergoes substitution with alkoxide to form ester and the reduced flavin $\mathbf{F l H}_{2}$ is re-oxidized by oxygen in a dark procedure. ${ }^{17,20 a, 24}$ Hydrogen peroxide, formed as a by-product, is decomposed by molecular sieves. ${ }^{9 c}$

Quantum yields of ester 6a production by methods I and II was found to be 0.04 and 0.07 , respectively, thus supporting closed catalytic cycle and indicating that an open radical propagation mechanism is not involved. We also not observed corresponding anhydride when monitoring the reaction mixture with $\mathbf{4 b}$ and $\mathbf{5 b}$ by ${ }^{1} \mathrm{H}$ NMR. Nevertheless presence of this alternative by-product/intermediate ${ }^{3 b, 5}$ in low concentration cannot be excluded.

\section{Conclusions}

In conclusion, we have shown for the first time that the original Mitsunobu reagents, DIAD (1b) and DEAD (1a), can be regenerated from the corresponding hydrazines by photocatalytic and/or organocatalytic system,${ }^{25}$ thus allowing esterifications that are catalytic in $\mathbf{1}$. The method is based on visible light and readily available riboflavin derivative $\mathbf{3 d}$, which is used in a catalytic amount, being recycled with molecular oxygen, an inexpensive and green terminal oxidant. The only drawback is side photooxidation of $\mathrm{Ph}_{3} \mathrm{P}$ to $\mathrm{Ph}_{3} \mathrm{P}=\mathrm{O}$ under aerial conditions, which can be eliminated by in situ backreduction. We have observed a completely new esterification pathway being involved in our photocatalytic esterification that occurs without any contribution from the azo compound $\mathbf{1}$ or hydrazine 2. It proceeds through $\mathrm{Ph}_{3} \mathrm{P}^{\cdot+}$ generated by photoinduced electron transfer to flavin. To the best of our knowledge, no similar synthetic application of photochemically generated $\mathrm{Ph}_{3} \mathrm{P}^{\cdot+}$ has hitherto been reported. As there is still room for improvement, optimization of both concepts is currently being pursued in our laboratories.

\section{Acknowledgements}

This project was supported by the Czech Science Foundation (Grant No. 16-09436S). R. C. thanks the German National Science Foundation (GRK 1626 "Chemical Photocatalysis").

\section{Notes and references}

$\ddagger$ Notably only trace of ester was formed in stoichiometric Mitsunobu reaction in the presence of hydrogen peroxide (1 equiv.) in acetonitrile while $90 \%$ of ester was formed after addition of MS 4A thus demonstrating $\mathrm{H}_{2} \mathrm{O}_{2}$-quenching of Mitsunobu reaction. Hydrogen peroxide was not detected by iodometry after photocatalytic esterifications in the presence of MS 4A.

$\S$ This value was not affected by either light or the flavin (see ESI $\dagger$ ).

ๆ Notably analogous formation of alkoxyphosphonium and acyloxyphosphonium species was observed when $\mathrm{Ph}_{3} \mathrm{P}^{\cdot+}$ was generated electrochemically, see ref. 26 .

1 (a) A. Voituriez and A. N. Saleh, Tetrahedron Lett., 2016, 57, 4443; (b) J. An, R. M. Denton, T. H. Lambert and E. D. Nacsa, Org. Biomol. Chem., 2014, 12, 2993; (c) J. Otera and J. Nishikido, in Esterification, Wiley-VCH Verlag $\mathrm{GmbH}$ \& Co. KGaA, 2010.

2 O. Mitsunobu and Y. Masaaki, Bull. Chem. Soc. Jpn., 1967, 40, 2380.

3 (a) S. Fletcher, Org. Chem. Front., 2015, 2, 739; (b) K. C. K. Swamy, N. N. B. Kumar, E. Balaraman and K. V. P. P. Kumar, Chem. Rev., 2009, 109, 2551; (c) T. Y. S. But and P. H. Toy, Chem. - Asian J., 2007, 2, 1340. 4 (a) J. McNulty, A. Capretta, V. Laritchev, J. Dyck and A. J. Robertson, Angew. Chem., Int. Ed., 2003, 42, 4051; 
(b) G. Wang, J.-R. Ella-Menye, M. St. Martin, H. Yang and K. Williams, Org. Lett., 2008, 10, 4203; (c) A. B. Hughes and M. M. Sleebs, J. Org. Chem., 2005, 70, 3079; (d) A. B. Smith, I. G. Safonov and R. M. Corbett, J. Am. Chem. Soc., 2002, 124, 11102; (e) C. Ahn and P. DeShong, J. Org. Chem., 2002, 67, 1754 .

5 S. Schenk, J. Weston and E. Anders, J. Am. Chem. Soc., 2005, 127, 12566.

6 T. Mukaiyama, Angew. Chem., Int. Ed. Engl., 1976, 15, 94.

7 A. J. Reynolds and M. Kassiou, Curr. Org. Chem., 2009, 13, 1610.

8 T. Y. S. But and P. H. Toy, J. Am. Chem. Soc., 2006, 128, 9636.

9 (a) D. Hirose, M. Gazvoda, J. Kosmrlj and T. Taniguchi, Chem. Sci., 2016, 7, 5148; (b) T. Hashimoto, D. Hirose and T. Taniguchi, Adv. Synth. Catal., 2015, 357, 3346; (c) D. Hirose, T. Taniguchi and H. Ishibashi, Angew. Chem., Int. Ed., 2013, 52, 4613.

10 T. Taniguchi, D. Hirose and H. Ishibashi, ACS Catal., 2011, 1, 1469.

11 C. J. O’Brien, PCT Int. Appl, WO2010/118042A2.2010, 2010.

12 J. A. Buonomo and C. C. Aldrich, Angew. Chem., Int. Ed., 2015, 54, 13041.

13 Very recently, idea on system catalytic both from the point of view of azo-compound and phosphine based on the above mentioned recycling agents was introduced (ref. 12) but realization is still subject of discussion; see: D. Hirose, M. Gazvoda, J. Kosmrlj and T. Taniguchi, Org. Lett., 2016, 18, 4036.

14 (a) N. A. Romero and D. A. Nicewicz, Chem. Rev., 2016, 116, 10075; (b) D. M. Schultz and T. P. Yoon, Science, 2014, 343, 985; (c) S. Fukuzumi and K. Ohkubo, Org. Biomol. Chem., 2014, 12, 6059; (d) D. Ravelli, M. Fagnoni and A. Albini, Chem. Soc. Rev., 2013, 42, 97.

15 S. Kümmel, R. Cibulka and B. König, in Chemical Photocatalysis, ed. B. König, de Gruyter, Berlin, 2013, p. 45.

16 (a) T. Neveselý, E. Svobodová, J. Chudoba, M. Sikorski and R. Cibulka, Adv. Synth. Catal., 2016, 358, 1654; (b) B. Mühldorf and R. Wolf, Angew. Chem., Int. Ed., 2016, 55, 427; (c) J. B. Metternich and R. Gilmour, J. Am. Chem. Soc., 2016, 138, 1040; (d) T. Hartman and R. Cibulka, Org. Lett., 2016, 18, 3710; (e) B. Mühldorf and R. Wolf, Chem Commun., 2015, 51, 8425-8428.

17 S. Fukuzumi, K. Yasui, T. Suenobu, K. Ohkubo, M. Fujitsuka and O. Ito, J. Phys. Chem. A, 2001, 105, 10501.

18 G. Jürmann, O. Tšubrik, K. Tammeveski and U. Mäeorg, J. Chem. Res., 2005, 661.

19 M. Yasuda, M. Nakai, Y. Kawahito and T. Shiragami, Bull. Chem. Soc. Jpn., 2003, 76, 601.

20 (a) J. Dad'ová, S. Kümmel, C. Feldmeier, J. Cibulková, R. Pažout, J. Maixner, R. M. Gschwind, B. König and R. Cibulka, Chem. - Eur. J., 2013, 19, 1066; (b) U. Megerle, R. Lechner, B. Konig and E. Riedle, Photochem. Photobiol. Sci., 2010, 9, 1400; (c) J. Svoboda, H. Schmaderer and B. König, Chem. - Eur. J., 2008, 14, 1854.

21 S. Fukuzumi, K. Shimoosako, T. Suenobu and Y. Watanabe, J. Am. Chem. Soc., 2003, 125, 9074.

22 (a) S. Yasui, S. Kobayashi and M. Mishima, J. Phys. Org. Chem., 2016, 29, 443; (b) S. Tojo, S. Yasui, M. Fujitsuka and T. Majima, J. Org. Chem., 2006, 71, 8227; (c) O. Kei, N. Takashi and F. Shunichi, Bull. Chem. Soc. Jpn., 2006, 79, 1489; (d) S. Yasui, S. Tojo and T. Majima, J. Org. Chem., 2005, 70, 1276.

23 A. Ehrenberg, F. Müller and P. Hemmerich, Eur. J. Biochem., 1967, 2, 286.

24 C. Feldmeier, H. Bartling, K. Magerl and R. M. Gschwind, Angew. Chem., Int. Ed., 2015, 54, 1347.

25 Oxidation of di-tert-butyl hydrazinedicarboxylate to azo compound with $\mathrm{CuI} / \mathrm{O}_{2}$ system was reported during preparation of the manuscript: D. Jung, M. H. Kim and J. Kim, Org. Lett., 2016, 18, 6300-6303.

26 (a) H. Maeda, T. Koide, T. Maki and H. Ohmori, Chem. Pharm. Bull., 1995, 43, 1076; (b) H. Ohmori, M. Maeda, M. Kikuoka, T. Maki and M. Masui, Tetrahedron, 1991, 47, 767. 